\title{
Pengaruh Excess Control Terhadap Cost Of Capital Dalam meningkatkan Profitabilitas
}

\author{
Hendra Gunawan, Rani Yessi Sinaga \\ Politeknik Negeri Batam \\ hendra@polibatam.ac.id; ranyyessi@gmail.com
}

\begin{abstract}
This study examines the effect of excess control on cost of capital seen from the profitability of the company to prove its effect on increasing the profitability of manufacturing companies. This study uses secondary data taken from the auditor's financial statements. The results show that excess control has a positive effect on cost of capital. The results of this study illustrate that capital will be good for the company if the funds are used effectively and efficiently. This research is important for companies and organizations, in order to be better in the use or utilization of capital in the company's operations. This company is only limited to manufacturing companies, so the next research is expected to be able to use samples from other industries.
\end{abstract}

Keywords: excess control, cost of capital

\begin{abstract}
Abstrak
Penelitian ini menguji pengaruh excess control terhadap cost of capital dilihat dari profitabilitas perusahaan untuk membuktikan pengaruhnya pada peningkatan profitabilitas perusahaan manufaktur. Penelitian ini menggunakan data sekunder yang yang diambil dari laporan keuangan auditor. Hasil menunjukan bahwa excess control berpengaruh positif terhadap cost of capital. Hasil penelitian ini menggambarkan modal akan baik bagi perusahaan bila dana tersebut digunakan secara efektif dan efisien. Penelitian ini penting bagi perusahaan maupun organisasi, agar lebih baik dalam penggunaan atau pemanfaatan modal dalam operasional perusahaan. Perusahaan ini hanya terbatas pada perusahaan manufaktur, sehingga penelitian berikutnya diharapkan dapat menggunakan sampel dari industri lainya.

Kata Kunci: excess control, cost of capital
\end{abstract}

Diterima: 8 Agustus 2018; Revisi: 2018; Disetujui: 2018 


\section{PENDAHULUAN}

Seiring dengan perkembangan teknologi di Indonesia khususnya di bidang ekonomi, perusahaan yang berbeda seharusnya mendapatkan perlakuan berbeda dalam menilainya. Oleh karena itu, menilai perusahaan harus berdasarkan tujuan perusahaan itu sendiri. Perbedaan tujuan bisa dilihat antara kepemilikan institusional dan kepemilikan manajerial (Zelganve \& Berzkalne, 2014).

Perusahaan keluarga merupakan sebuah entitas bisnis yang memiliki karakteristik berbeda yang tidak dimiliki oleh perusahaan pada umumnya. Perusahaan keluarga memiliki visi jangka panjang yang solid karena adanya kepemilikan lebih dan komitmen jangka panjang yang jelas. Perusahaan umumnya memiliki fleksibilitas dan kecepatan pengambilan keputusan yang tinggi karena perusahaan dikelola oleh manajer-manajer sekaligus menjadi pemilik.

Modal merupakan dana yang digunakan untuk membiayai pengadaan aset dan operasional suatu perusahaan. Cost of capital merupakan pengembalian yang dapat diharapkan oleh investor suatu perusahaan apabila mereka berinvestasi pada sekuritas-sekuritas yang mempunyai tingkat risiko yang sebanding. Perhitungan biaya modal sangat penting karena dapat memaksimalkan nilai perusahaan dan mengharuskan biaya termasuk biaya modal yang diminimumkan.

Perbedaan penelitian ini dengan penelitian sebelumnya yaitu dari tahun pengamatan penelitian. Penelitian yang dilakukan oleh Berzkalne (2014) mengamati perusahaan sektor manufaktur yang terdaftar di Bursa Efek Indonesia pada tahun 2002-2005, sedangkan pada penelitian ini peneliti menggunakan sampel perusahaan manufaktur pada tahun 2015-2016. Hal ini dikarenakan peneliti ingin memberikan informasi terkini terkait dengan pengaruh excess control terhadap cost of capital.

Cost of capital adalah biaya yang dikeluarkan untuk membiayai sumber pembelanjaan (Modigliani \& Miller, 1959; Dempsey, 1991). Biaya modal adalah biaya riil yang harus ditanggung perusahaan karena digunakannya modal yang digunakan untuk berinvestasi. Biaya modal juga diartikan sebagai batas minimum tingkat hasil yang harus dicapai perusahaan agar perusahaan tidak dinyatakan rugi. 
Laporan keuangan merupakan bagian utama dalam pelaporan keuangan yang dapat dijadikan sarana penting untuk mengkomunikasikan informasi kepada pihak-pihak yang berkepentingan terhadap perusahaan yaitu pemegang saham, kreditor, pemerintah, dan sebagainya. Lampiran keuangan bertujuan untuk memberikan informasi kepada pemakai laporan agar dapat membantu menterjemahkan aktivitas ekonomi dari suatu perusahaan, oleh karena itu laporan keuangan menjadi perhatian utama bagi penggunanya untuk mengambil keputusan (Gunawan \& Ramadhani, 2018).

Exces control merupakan perbedaan antara hak pemungutan suara dan arus kas, biasanya dicapai melalui penggunaan mekanisme kontrol dilihat dari meningkatkan saham dan kepemilikan. Kepemilikan investor yang lemah meningkatkan biaya modal yang lebih tinggi. Menurut penelitian oleh (Darmadji \& Fakhruddin, 2001), saham adalah tanda penyertaan atau kepemilikan seseorang atau badan dalam suatu perusahaan atau perseroan terbatas. Cost of capital merupakan pengembalian yang dapat diharapkan oleh investor suatu perusahaan apabila mereka berinvestasi pada sekuritas-sekuritas yang mempunyai tingkat risiko yang sebanding. Cost of capital adalah biaya yang dikeluarkan untuk membiayai sumber pembelanjaan (Modigliani dan Miller, 1959: Dempsey, 1991). Biaya modal merupakan biaya riil yang harus ditanggung perusahaan karena digunakannya modal yang digunakan untuk berinvestasi. Mengingat sifatnya sebagai biaya, maka biaya modal juga diartikan sebagai batas minimum tingkat hasil yang harus dicapai perusahaan agar perusahaan tidak dinyatakan rugi.

Berdasarkan penelitian yang dilakukan, mereka menguji pengaruh excess control terhadap cost of capital yang memiliki hasil berbeda beda yaitu penelitian yang dilakukan oleh Modigliani dan Miller (2013), Zelganve (2014), Berzkalne (2014), Sien (2006), Sujoko (2007).

Besar kecilnya excess control berpengaruh terhadap cost of capital perusahaan. Semakin besar excess control maka semakin besar pula cost of capital perusahaan. Perusahaan yang mengontrol perusahaannya secara menyeluruh akan akan memiliki cost of capital yang baik. Penelitian yang dilakukan oleh 
Ashbaug et al,. (2004) menguji pengaruh hubungan kualitas dan tata kelola biaya modal dan menemukan bahwa hubungan negatif antara kualitas pemerintah dan biaya hutang menghubungkan biaya keseluruhan modal dengan perlindungan investor pemerintah dan kepemilikan variabel perusahan.

Excess control perbedaan antara hak pemungutan suara dan arus kas biasanya dicapai melalui penggunaan mekanisme kontrol meningkatkan seperti saham dan kepemilikan (Bebchuk 2000). Penelitian ini merujuk pada penelitian sebelumnya yang dilakukan oleh Bozez (2012) yang menemukan hasil terdapat pengaruh antara excess control dengan biaya modal. Biaya modal dapat meningkat dengan adanya kelebihan kontrol dalam suatu perusahaan keluarga maupun perusahaan manajerial. ost of capital merupakan pengembalian yang dapat diharapkan oleh investor suatu perusahaan apabila mereka berinvestasi pada sekuritas-sekuritas yang mempunyai tingkat risiko yang sebanding. Cost of capital adalah biaya yang dikeluarkan untuk membiayai sumber pembelanjaan (Modigliani dan Miller, 1959: Dempsey, 1991). Biaya modal adalah biaya riil yang harus ditanggung perusahaan karena digunakannya modal yang digunakan untuk berinvestasi.

\section{METODE}

Jenis data yang digunakan adalah data sekunder, penelitian ini dilakukan pada perusahaan manufaktur dalam bentuk laporan keuangan yang telah diaudit yang terdaftar di Bursa Efek Indonesia (BEI) periode 2015-2016.

Teknik pengambilan sampel pada penelitian ini dilakukan secara purposive sampling menggunakan kriteria-kriteria berupa suatu pertimbangan tertentu. Kriteria sampel pada penelitian ini adalah perusahaan manufaktur dan sudah terdaftar pada Bursa Efek Indonesia (BEI) selama periode tahun 2015-2016.

Purposive sampling merupakan pengambilan suatu keputusan dengan tujuan tertentu, pengambilan sampel secara sengaja sesuai dengan persyaratanpersyaratan yang diperlukan, sifat-sifat, karakteristik, ciri dan kriteria. Kriteriakriteria yang diperlukan yaitu: (1)Perusahaan yang memiliki laporan keuangan yang telah diaudit; (2) Laporan keuangan yang dalam mata uang rupiah (Rp); (3) 
Perusahaan yang memiliki data yang lengkap terkait variabel yang digunakan dalam penelitian.

Teknik pengumpulan data yang digunakan dalam penelitian ini adalah teknik pengumpulan data arsip dengan menggunakan teknik pengumpulan data di basis data untuk mendapatkan data sekunder berupa laporan keuangan perusahaan manufaktur yang terdaftar di BEI tahun 2015-2016.

Peneliti melakukan cara dalam mengolah data yang telah dikumpulkan dari annual report Bursa Efek Indonesia (BEI). Menentukan variabel yang dibutuhkan untuk penelitian ke dalam spreadsheet, memasukkan rumus yang sudah ditetapkan dalam operasional variabel. Pengujian yang dilakukan menggunakan data cross section. Metode analisis penelitian ini menggunakan regresi linear sederhana.

\section{HASIL DAN PEMBAHASAN}

Data yang digunakan dalam penelitian ini yaitu perusahaan manufaktur terdaftar di Bursa Efek Indonesia (BEI) selama periode 2015-2016 yaitu berjumlah 137 perusahaan. Namun terdapat pengurangan sampel sesuai kriteria sampel yang ditetapkan yang ditetapkan oleh peneliti. Perusahaan yang tidak memiliki data yang lengkap sesuai variabel yang dibutuhkan peneliti sebanyak 48 perusahaan pada tahun 2015-2016.

Berdasarkan pengurangan sampel yang dilakukan, total sampel yang digunakan sebanyak 89 perusahaan tahun 2015-2016.

Tabel 1. Hasil Perhitungan Sampel

\begin{tabular}{ll}
\hline Indikasi Perusahaan Tahun 2016 & \\
\hline Perusahanan manufaktur terdaftar di BEI & 137 \\
Perusahaan yang tidak memiliki data lengkap & 30 \\
Perusahaan tidak melaporkan laporan keuangan & 18 \\
Jumlah & 89 \\
\hline
\end{tabular}

Sumber: Data diolah

Dari hasil uji statistik secara deskriptif dapat diketahui jumlah atau nilai dari mean, median, minimum, dan maksimum data. Nilai variabel excess control mean 12,5036, median 12,5036, minimum 3,9988, maksimum 38.3493 dan nilai 
variabel cost of capital mean 2,4159, median 2,4159, minimum 1,3859, maksimum 3,6467 .

Tabel 2. Uji Heteroskedastisitas

\begin{tabular}{lll}
\hline Keterangan & $\mathbf{t}$ & Sig \\
\hline Coc & 12,511 & 0,000 \\
Excess & 2,182 & 0,032 \\
\hline
\end{tabular}

Sumber: Data diolah

Menguji heterokedastisitas menggunakan uji signifikansi data dan perbandingan antara nilai thitung dengan ttabel. Tingkat signifikansi dalam pengujian ini, dilihat dari nilai sig sedangkan nilai thitung dilihat dari nilai t. Nilai t tabel dengan $\mathrm{N}=89$ adalah 1,986. Tampilan output pada variabel cost of capital menunjukkan nilai sig 0,000 $<0,05$ dan nilai t 12,511 $<1,986$ dan variabel excess control sig 0,032 < 0,05 dan nilai t 2,182 < 1,986. Maka dapat disimpulkan bahwa hasilnya.

Tabel 3. Uji Regresi Linear sederhana

\begin{tabular}{llll}
\hline Model & B & T & Sig \\
\hline 1 (constant) & 15,547 & 12,551 &, 000 \\
Excess excess &, 195 & 2,182 &, 032 \\
\hline
\end{tabular}

Sumber: Data diolah

Berdasarkan Tabel 3 dapat disimpulkan persamaan regresi linear sederhana sebagai berikut.

$$
\mathrm{Y}=15,547+(0,195) \text { Excess }
$$

Tampilan output menunjukan nilai t hitung sebesar 2,182 dengan signifikan 0,32. Nilai signifikan tersebut lebih kecil dari 0,05 sehingga dapat disimpulkan bahwa hipotesis terdukung. Berdasarkan uji statistik yang dilakukan, bahwa hasil pengujian variabel independen yaitu excess control berpengaruh terhadap variabel dependen cost of capital.

Berdasarkan hasil uji statistik, variabel excess control berpengaruh positif terhadap cost of capital. Hal ini berarti semakin bertambah excess control maka semakin bertambah pula cost of capital. Excess control berpengaruh positif terhadap cost of capital karena perusahaan mampu mengelola secara efektif 
sehingga cost of capital perusahaan semakin meningkat. Hasil penelitian ini berbeda dengan penelitian yang dilakukan oleh Shinta (2014) dan Mohammad dan Abdullah (2012).

\section{SIMPULAN}

Berdasarkan hasil pengujian hipotesis di atas bahwa excess control berpengaruh positif terhadap cost of capital karena perusahaan mampu mengelola secara efektif sehingga cost of capital perusahaan semakin meningkat. Penelitian ini berisikan suatu model untuk menguji pengaruh excess control terhadap cost of capital berdasarkan hasil pengujian regresi. Dapat disimpulkan bahwa excess control berpengaruh positif terhadap cost of capital pada perusahaan yang terdaftar di Bursa Efek Indonesia periode 2015-2016.

Terdapat beberapa keterbatasan yang dapat berpengaruh pada hasil penelitian. Sektor perusahaan yang digunakan dalam penelitian ini hanya menggunakan perusahaan manufaktur dan periode digunakan dua periode 20152016, sehingga jarang dapat mencerminkan hasil secara keseluruhan dan periode yang pendek. Implikasi pada penelitian ini ditujukan pada perusahaan manufaktur mengenai excess control terhadap cost of capital perusahaan.

\section{PUSTAKA ACUAN}

Allaire, Y., \& Firsirotu, M. 2009. Black Market and Business Blues. F1 Press, Montreal.

Altman. E. I. 1968. Financial Ratios, Discriminant Analysis and the Prediction of Corporate Bankruptcy. Journal of Finance, 23(4), 189-209.

Ashbough, H., Collins, D. W., \& Lafond, R. 2004. Corvorate Governance on the Cost of Equity Capital. Working Paper, The Social Science Research Network, Electronik library, available: www.ssrn.com.id.

Attig, N,. Fong, W. M. Gadhoum, Y. and Lang, L. H. P. 2006. Effects of Large Shareholding on information Asymmetry and Stock Liquidity, Journal of Banking \& Finance, 30(10), pp. 2875-2892. 
Baek, J. S., Kang, J. K and Park, K. S. 2004. Corvorate Governance and Firm Value: Evidence from the Corean Financial Crisis, Journal of Financial Economic, 71(4), pp. 265-313.

Barontini, R. and Caprio, L. 2006. The Effect of Ownhership Structure and Family Control on Firm Value; Evidence from Continental Europe. Eropean Financial Management, 12(5), pp. 689-723.

Bebehuk, L., Krakman, R, and Triantis, G. 2000. Stock Pyramids CrossOwnhwership, and Dual Class Equity; The Creation and Agency Cost of Separating Control from Cash Flow Rights. Randall, K.M. (Ed), Concentrated Corporate Ownershipe, University of Chicago Press, Chichgo, II, pp. 295315.

Bierman, H. Jr. 1993. Capital Budgeting in 1992; a survey. Financial management, 22(3), pp. 24.

Bhojraj, S and Sengupta, P. 2003. Effect of Corvorate Governance on Bond Ratings and Yields; the Role of Institutional Investors and Outside Directors. Journal of Business, 76(3), pp. 455-475.

Booth, L,. 2001. Equity Market Risk Premiums in the US and Canada. Canadion Investment Review, Fall, pp. 4-43.

Boubakri, N., Bozec, C. 2004. Concentration des Droits de Propiete, Separation Entre Structure, and Firm Value: Evidence from Canada. Journal of Empirical Legal Studies, 8(2), pp.358-383.

Bozec, Y. and Laurin. C. 2008. Large Shareholder Entrenchment and Performance; Empirical Evidence from Canada. Journal of Business Finance and Accounting, 35(1), pp. 25-49.

Gunawan, H., \& Ramadhani, W. 2018. How Intellectual Capital Effects Firm's Financial Performance. Journal of Applied Accounting and Taxation, 3(1), 18. https://doi.org/10.5281/zenodo.1304936. 